\title{
Immuno-enhancement effects of Platycodon grandiflorum extracts in splenocytes and a cyclophosphamide- induced immunosuppressed rat model
}

Eun-Mi Noh ${ }^{1 \dagger}$, Jeong-Mi Kim ${ }^{1 \dagger}$, Hak Yong Lee ${ }^{2}$, Hyun-Kyung Song ${ }^{1}$, Sang Ok Joung ${ }^{3}$, Hye Jeong Yang ${ }^{4}$, Min Jung Kim ${ }^{4}$, Kang Sung $\mathrm{Kim}^{5}$ and Young-Rae Lee ${ }^{1 *}$ (D)

\begin{abstract}
Background: Platycodon grandiflorum is a flowering plant that is used in traditional medicine for treating pulmonary and respiratory disorders. It exerts various pharmacological effects, including immunomodulatory and anti-cancer activities. The purpose of this study was to confirm the in vitro and in vivo immune-enhancing effects of P. grandiflorum extract (PGE) on splenocytes isolated from cyclophosphamide (CP)-induced immunosuppressed rats.

Methods: For in vitro analysis, splenocytes were treated with PGE at various doses along with CP. Cell viability was measured by a WST-1 assay, and NK cell activity and cytotoxic T lymphocyte (CTL) activity was also examined. In addition, immunoglobulin A (IgA), IgG, and cytokine levels were measured. For in vivo analysis, Sprague Dawley rats were treated with various doses of PGE along with CP. Complete blood count (CBC) was performed, and plasma levels of IgA, IgG, TNF-a, IFN- $\gamma$, IL-2, and IL-12 were quantified. Additionally, tissue damage was assessed through histological analyses of the thymus and spleen.

Results: PGE treatment enhanced cell viability and natural killer cell and cytotoxic T lymphocyte activity, and increased the production of CP-induced inflammatory cytokines (TNF- $a, I F N-\gamma, I L-2$, and IL-12) and immunoglobulins ( IgG and $\lg A$ ) in splenocytes. In addition, in CP-treated rats, PGE treatment induced the recovery of white blood cell, neutrophil, and lymphocyte counts, along with mid-range absolute counts, and increased the serum levels of inflammatory cytokines (TNF-a, IFN- $\gamma$, IL-2, and IL-12) and immunoglobulins (IgG and IgA). Moreover, PGE attenuated CP-induced spleen and thymic damage.

Conclusions: Our results confirmed that PGE exerts an immune-enhancing effect both in vitro and in vivo, suggesting that PGE may have applications as a component of immunostimulatory agents or as an ingredient in functional foods.
\end{abstract}

Keywords: Platycodon grandiflorum, Immunostimulation, Cyclophosphamide, Cytokine, Immune cells

* Correspondence: mindyr@wku.ac.kr

${ }^{\dagger}$ Eun-Mi Noh and Jeong-Mi Kim contributed equally to this work.

${ }^{1}$ Department of Oral Biochemistry, and Institute of Biomaterial-Implant,

College of Dentistry, Wonkwang University, 460, Iksandae-ro, Iksan, Jeonbuk

54538, Republic of Korea

Full list of author information is available at the end of the article

(c) The Author(s). 2019 Open Access This article is distributed under the terms of the Creative Commons Attribution 4.0 International License (http://creativecommons.org/licenses/by/4.0/), which permits unrestricted use, distribution, and reproduction in any medium, provided you give appropriate credit to the original author(s) and the source, provide a link to the Creative Commons license, and indicate if changes were made. The Creative Commons Public Domain Dedication waiver (http://creativecommons.org/publicdomain/zero/1.0/) applies to the data made available in this article, unless otherwise stated. 


\section{Background}

Platycodon grandiflorum (PG) roots have traditionally been used as a herbal medicine and food for the treatment of various pulmonary diseases and respiratory disorders in China, Japan, and Korea [1]. PG has been found to contain numerous chemical components, including saponins, polysaccharides, flavonoids, phenolic acids, fatty acids, and sterols [2]. In addition, PG performs various pharmacological activities that have anti-diabetic [3], anti-cancer [4], anti-inflammatory [5], immunomodulatory [6], and antiallergic [7] effects.

Organs of the immune system, such as the bone marrow, thymus, lymph nodes, and spleen, play a major role in mediating the immune response and to ensure that a protective response to negate the effects of harmful stimuli is established [8]. These highly sophisticated and complex biological responses involve macrophages, dendritic cells, and various immune cells, including lymphocytes [9]. Lymphocytes, which comprise white blood cells, can be divided into $\mathrm{T}$ cells, $\mathrm{B}$ cells, and natural killer cells (NK). NK cells belong to the innate immune system and play a major role in defending the host from cancer cells, bacteria, and virus-infected cells [10]. T cells and secreted cytokines are associated with adaptive or cell-mediated immune responses, whereas B cells and antibodies are key factors in the humoral immune response [11]. Further, the imbalances in the immune system are associated with autoimmune diseases and disorders caused by inflammatory responses in various organs [12].

Cyclophosphamide (CP), a commonly used alkylating agent for chemotherapy, exerts myelosuppressive, immunosuppressive, and cytotoxic effects [13, 14]. Administration of CP can lead to a sudden change in Th1/Th2 bias, resulting in immunosuppression. In previous studies, the immunological effects of $\mathrm{CP}$ were found to decrease the proliferation of $\mathrm{T}$ cells along with the levels of secreted Th1 cytokines (tumor necrosis factor [TNF]- $\alpha$, interferon [IFN]- $\gamma$, interleukin [IL]-2, and IL-12) and Th2 cells (IL-4, IL-6, and IL-10) $[15,16]$.

In order to develop potential immune-enhancing agents that can be used as components of functional foods, increasing attention is being paid to the immunomodulatory properties of plants with a broad spectrum of therapeutic properties, as plant-based therapeutic agents are associated with relatively low toxicities $[17,18]$. Although a recent report indicated that PG exerts an anti-tumor effect by improving the immune function [19], to our knowledge, no data are available regarding its immuneenhancing effects in a CP-induced immunosuppression model. Therefore, in the present study, we confirmed the in vitro and in vivo immune-enhancing effects of PG extract (PGE) on splenocytes isolated from immunosuppressed rats generated by $\mathrm{CP}$ administration.

\section{Methods}

\section{Preparation of PGE}

PG was manufactured by JIRISANDONGUICHON Co. Ltd. (Sancheong-Gun, Gyeongnam, Korea). It was formally identified by the Rural Development Administration of the Korean Government. The dried roots of PG were purchased from JIRISANDONGUICHON, and a voucher specimen (no. 180426) was deposited at INVIVO Co. Ltd., Iksan, Korea. The extract was prepared as follows: briefly, the dried roots $(100 \mathrm{~g})$ were extracted in an electric boiling pot for $3 \mathrm{~h}$ with 1000 $\mathrm{mL}$ of distilled water at $100^{\circ} \mathrm{C}$, and filtered using a $0.45-\mu \mathrm{m}$ syringe filter. The extract solution was evaporated under $40 \mathrm{mmHg}$ using a rotary evaporator $(\mathrm{N}$ 1110S-W; Eyela, Tokyo, Japan), and was then used for each experiment.

The main components present in PGE were analyzed using an HPLC system (Shimadzu LC-30 Series, Shimadzu Corporation, Nakagyo-ku, Kyoto, Japan) with an SHISEIDO Capcell Pak C18 column ( $3.0 \mathrm{~mm}$ i.d. $\times 50 \mathrm{~mm}, 3 \mu \mathrm{m})$. Signals were detected using a MS system (Shimadzu LCMS8030, Shimadzu Corporation, Nakagyo-ku, Kyoto, Japan). The levels of Platycodin D in PGE were quantitated using a calibration curve established by injecting dilutions of each Platycodin D standard (1-10 $\mu \mathrm{g} / \mathrm{mL})$ into the HPLC system (correlation coefficient $\geq 0.996$ ). Standards (Platycodin D) for HPLC analysis were obtained from Sigma-Aldrich ( $\mathrm{St}$ Louis, MO, USA).

\section{Animals}

Animal experiments were performed as previously described [20]. Sprague Dawley (SD) rats were purchased from Samtaco Inc. (Osan, Gyeonggi-do, Korea), and acclimated to the following environmental conditions for 7 days: 12 -h light/12-h dark cycle; temperature, $23 \pm 1{ }^{\circ} \mathrm{C}$; humidity, $50 \pm 5 \%$; and illumination, $150-300 \mathrm{~lx}$. Rats were randomly assigned to five groups (10 rats per group). The protocols used for these animal studies were approved by the Committee on Care and Use of Laboratory Animals of Wonkwang University (Iksan, Jeollabukdo, Korea; approval no. WKU18-17).

\section{Cell culture}

Cells were cultured as previously described [20]. Briefly, the spleen of an 8-week-old SD rat was aseptically dissected to obtain splenocytes. The spleen was gently pressed with forceps and then forced through a 70- $\mu \mathrm{m}$ cell strainer (SPL Life Sciences, Pocheon-si, Gyeonggido, Korea). Cells were treated with red blood cell lysis buffer (Sigma-Aldrich, St. Louis, MO, U.S.A.). Isolated splenocytes were incubated in RPMI-1640 containing $10 \%$ fetal bovine serum (FBS) and 1\% antibiotics (penicillin, streptomycin) (Invitrogen) in a $5 \% \mathrm{CO}_{2}$ incubator. 


\section{Cell viability}

Cell viability were performed as previously described [20], using a WST-1 Assay Kit (ITSBio, Seoul, Gyeonggi-do, Korea) according to the manufacturer's instructions. Briefly, splenocytes $\left(2 \times 10^{5}\right.$ cells/well $)$ were seeded into 96-well plates and then treated with PGE at various doses along with CP $(1600 \mu \mathrm{g} / \mathrm{mL})$, and incubated for $24 \mathrm{~h}$ in an incubator with $5 \% \mathrm{CO}_{2}$ atmosphere. Cell viability was assessed using a WST-1 Assay Kit and a microplate plate reader (Tecan, Männedorf, Switzerland).

\section{NK cell activity assay}

NK cell activity was measured as previously described [20]. Briefly, AR42J rat pancreas tumor cells obtained from the American Type Culture Collection (ATCC, Manassas, Va., U.S.A.) AR42J cells were used as target cells for the NK cell activity assay, and splenocytes were used as effector cells. Splenocytes were co-cultured with AR42J cells in 96-well plates at a 25:1 ratio of effector cells to target cells. The viability of AR42J cells was assessed using a CytoTox detection kit (TaKaRa, Shiga, Japan) and a microplate plate reader. NK cell activity was calculated as the viability of AR42J cells compared to control cells.

\section{Cytotoxic T lymphocyte (CTL) activity assay}

CTL activity was determined as previously described [20]. Briefly, CTL activity was analyzed using the CytoTox detection kit (TaKaRa) according to the manufacturer's protocol. Tumor cells (HL-60) obtained from ATCC were used as target cells for the CTL assay, and an effector cell to target cell ratio of 25:1 was used. CTL activity was calculated as the survival rate of HL-60 cells compared to that of control cells.

\section{Measurement of immunoglobulin a $(\lg A), \lg G$, and cytokine levels in splenocytes}

Immunoglobulin (Ig) and cytokine levels were measured as previously described [20]. Briefly, splenocytes $\left(2 \times 10^{5}\right.$ cells/well) were seeded into 96-well plates, after which cells were treated with various concentrations of PGE (0, $10,30,50,100,300$, or $500 \mu \mathrm{g} / \mathrm{mL})$ and $\mathrm{CP}(1600 \mu \mathrm{g} /$ $\mathrm{mL}$ ), and incubated for $24 \mathrm{~h}$. The levels of IgA and IgG were measured using an immunoglobulin ELISA kit (AFFymetrix, Santa Clara, Ca., U.S.A and Abcam, Cambridge, U.K.) according to the manufacturer's instructions. The levels of TNF- $\alpha$, IFN- $\gamma$, IL-2, and IL-12 in the culture medium measured using Cytokine Activation Analysis Kits (R\&D Systems, Minneapolis, MN, U.S.A.), according to the manufacturer's instructions. The immunoglobulin and cytokine levels were measured using an ELISA reader.

\section{Complete blood count (CBC) and IgA, IgG, and cytokine analyses}

These analyses were conducted as previously described [20]. Briefly, SD rats were orally administered PGE (0, 10 , 30 , or $100 \mathrm{mg} / \mathrm{kg} /$ day $)$ and CP $(5 \mathrm{mg} / \mathrm{kg}$, once per day) for 28 days. After the final drug administration, rats were weighed and anesthetized with $5 \%$ isoflurane. Whole blood was collected. Next, the rats were euthanized by exsanguination. The numbers of white blood cells (WBCs), lymphocytes, neutrophils, and mid-range absolute counts (MID) were measured using a Hemavet 950 system (Drew Scientific Group, Dallas, Tx., U.S.A.). The levels of IgA, IgG, TNF- $\alpha$, IFN- $\gamma$, IL-2, and IL-12 in the plasma were quantified using ELISA kits, according to the manufacturer's instructions.

\section{Thymus and spleen histochemical analyses}

Histochemical analyses of the thymus and spleen were performed as previously described [20]. Thymus and spleen tissues were fixed in $10 \%$ neutral buffered formalin. The organs were then processed for dehydrating with alcohol and embedding in paraffin. Samples were cut to 4- $\mu \mathrm{m}$-thick section and stained with hematoxylin and eosin. Tissue damage was evaluated under a microscope.

\section{Statistical analysis}

All experimental data are presented as mean \pm standard error (SE), calculated using the statistical program SPSS version 12.0 (SPSS Inc., Chicago, IL, U.S.A). Results were analyzed by a one-way analysis of variance (ANOVA) and Duncan's multiple range tests using SAS software (version 9.3; SAS Institute Inc., Cary, NC., U.S.A.). Pvalues $<0.05$ were considered statistically significant.

\section{Results}

\section{HPLC analysis of PGE}

The physiological activity of Platycodon grandiflorum is attributed to the active compound, platycodin D. We performed LC-MS/MS analysis of the PGE, and found that PGE contained primarily platycodin D at a concentration of $22.6 \mathrm{mg} / \mathrm{L}$ (Fig. 1).

\section{Effect of PGE on CP-induced splenocyte viability}

To confirm the cytotoxicity of PGE against splenocytes, cells were incubated with various concentrations of PGE $(0,1,3,5,10,30,50,100,300,500,1000$, or $3000 \mu \mathrm{g} /$ $\mathrm{mL}$ ) for $24 \mathrm{~h}$. Cell viability was not effected at PGE concentrations $<500 \mu \mathrm{g} / \mathrm{mL}$ (Fig. 2a). Therefore, $500 \mu \mathrm{g} / \mathrm{mL}$ was considered the optimal non-toxic concentration, and subsequent in vitro experiments were performed at a PGE concentration of $<500 \mu \mathrm{g} / \mathrm{mL}$. To investigate splenocyte viability, cells were incubated with CP $(1600 \mu \mathrm{g} / \mathrm{mL})$ and PGE $(0,1,3,5,10,30,50,100,300$, or 


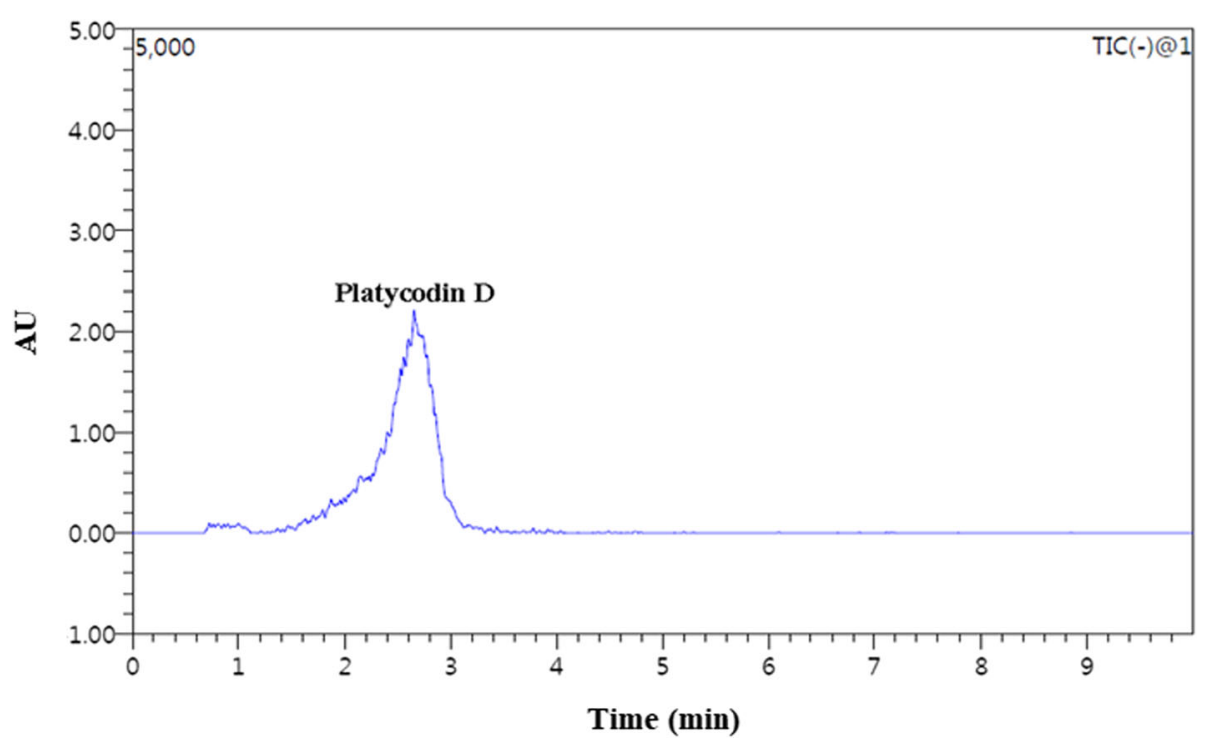

Fig. 1 Representative high-performance liquid chromatography profile of PGE. Platycodin D was detected by LC-MS/MS

$500 \mu \mathrm{g} / \mathrm{mL}$ ) for $24 \mathrm{~h}$. We found that PGE increased cell viability in a dose-dependent manner (Fig. 2b), indicating that PGE mitigates the reduction in cell proliferation caused by $\mathrm{CP}$-induced immunosuppression.

\section{Effect of PGE on cytokine expression in CP-treated splenocytes}

To confirm the effect of PGE on production of cytokines by splenocytes, cells were incubated with CP $(1600 \mu \mathrm{g} /$ $\mathrm{mL})$ and PGE $(0,10,30,50,100,300$, or $500 \mu \mathrm{g} / \mathrm{mL})$ for 24h. PGE increased cytokine levels in a dose-dependent manner (Fig. 3), which confirmed that PGE attenuates the CP-induced reduction in TNF- $\alpha$, IFN- $\gamma$, IL-2 and IL12 production by splenocytes.

\section{Effects of PGE on IgG and IgA levels in CP-treated splenocytes}

To understand the mechanism underlying the immunoregulatory activity of PGE, levels of IgG and IgA in CPtreated splenocytes were determined by ELISA. As

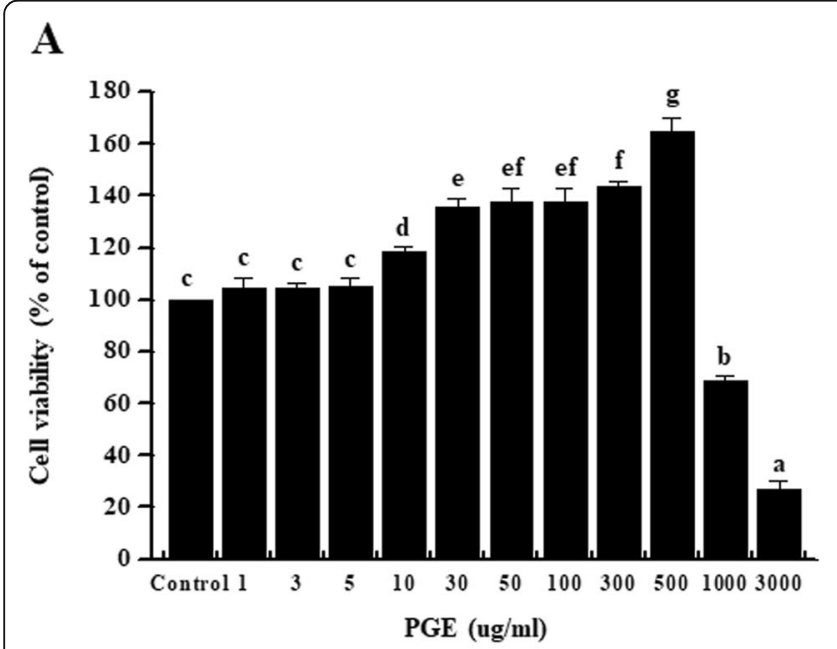

B

Fig. 2 Effect of PGE on cytotoxicity of splenocytes and cell viability of CP-treated splenocytes. a Splenocytes were seeded into a 96-well plate with PGE $(0,1,3,5,10,30,50,100,300,500,1000$, and $3000 \mu \mathrm{g} / \mathrm{mL})$. b Splenocytes were treated with PGE $(0,1,3,5,10,30,50,100,300$, and $500 \mu \mathrm{g} / \mathrm{mL})$ and/or CP $(1600 \mu \mathrm{g} / \mathrm{mL})$. Cells were incubated for $24 \mathrm{~h}$ in under $5 \% \mathrm{CO}_{2}$, and their viability was measured using a WST-1 Assay Kit. Bars labeled with different superscripts indicate significant differences $(P<0.05)$. Data are presented as the means \pm standard errors $(n=3)$ 


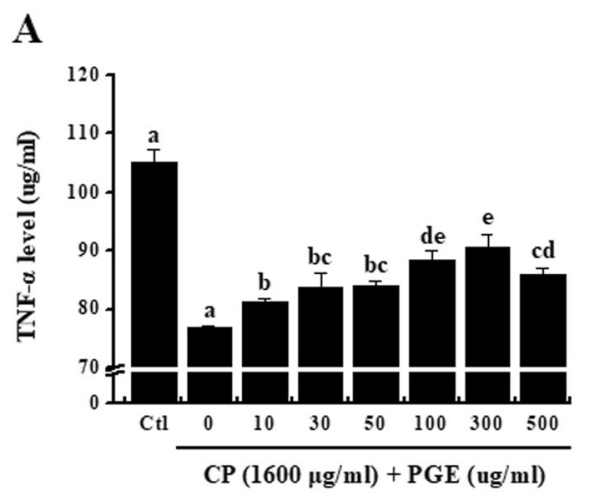

C

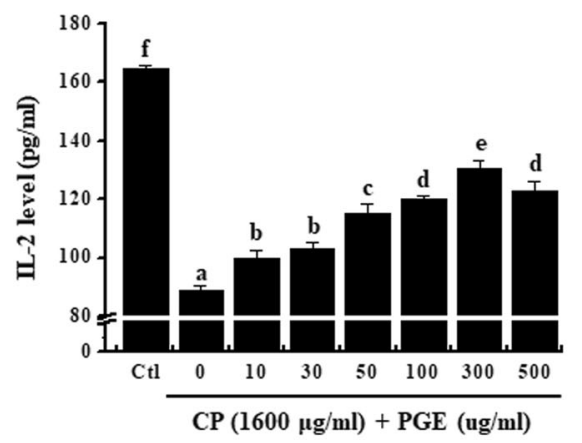

B

D
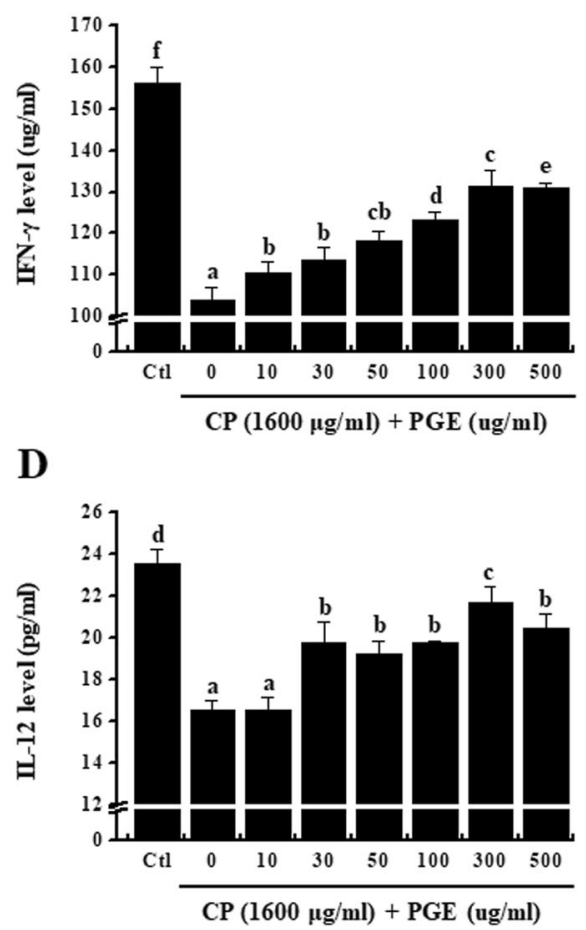

Fig. 3 Effect of PGE on cytokine levels in CP-treated splenocytes. Cells were seeded into 96-well plates, followed by treatment with PGE (0, 10, 30,

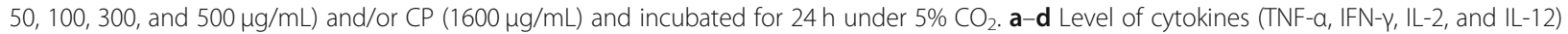
secreted into the culture medium was analyzed using ELISA kits. Bars labeled with different superscripts have significantly different values $(P<$ 0.05). Data are presented as the means \pm standard errors $(n=3)$

shown in Fig. 4, IgG and IgA levels were significantly decreased upon CP-treatment. However, PGE-treated splenocytes exhibited increased levels of IgG and IgA compared with non-PGE-treated cells, suggesting that PGE improves the humoral immune response.

\section{Effects of PGE on NK and CTL cytotoxicity in splenocytes} NK cells and CTLs are cytotoxic lymphocytes [21] that mediate the defense against tumor cells and virus-infected cells. Therefore, we examined the effects of PGE on NK cell and CTL activity. Splenocyte cytotoxicity was tested against NKsensitive tumor cells (AR42J) and CTL-sensitive HL60 cells. As shown in Fig. 5, NK cell and CTL activity were significantly increased after exposure to PGE in a dose-dependent manner, suggesting that PGE can improve the cell immune function in CPimmunosuppressed rats.

\section{Effect of PGE on immune cell number in rats}

The immune response is mediated by immune cells, such as $\mathrm{T}$ and $\mathrm{B}$ lymphocytes, mononuclear cells, and macrophages; thus, these cells play an important role in immune regulation [22-24]. As immunosuppressants such as cyclophosphamide can be used to reduce the population of immune cells, we analyzed the effect of PGE on the cytokine level in immunosuppressed rats that were generated through $\mathrm{CP}$ administration. Our results showed that PGE treatment increased the number of WBCs, lymphocytes, MID, and neutrophils in CPtreated rats (Fig. 6).

\section{Effect of PGE on serum levels of immune-related cytokines in CP-induced immunosuppressed rats} To confirm the effects of PGE on immune-related cytokine expression, we investigated the levels of TNF- $\alpha$, IFN- $\gamma$, IL-2, and IL-12 in the serum of immunosuppressed rats treated with $\mathrm{PGE}$ and/or $\mathrm{CP}$ (Fig. 7). The level of each of these cytokines was reduced in the serum in immunosuppressed rats (CPtreated) as compared to normal rats (saline-treated). In addition, the PGE-treated group showed a significant increase in the plasma levels of TNF- $\alpha$ and IL-2, compared with the non-PGE treated group, whereas IFN- $\gamma$ and IL-12 levels showed attenuation in reduction in expression after being upregulated at $10 \mathrm{mg} / \mathrm{kg}$ PGE treatment. These results indicate that PGE alleviates the immunosuppression induced by $\mathrm{CP}$ treatment by restoring the cytokine production capacity. 


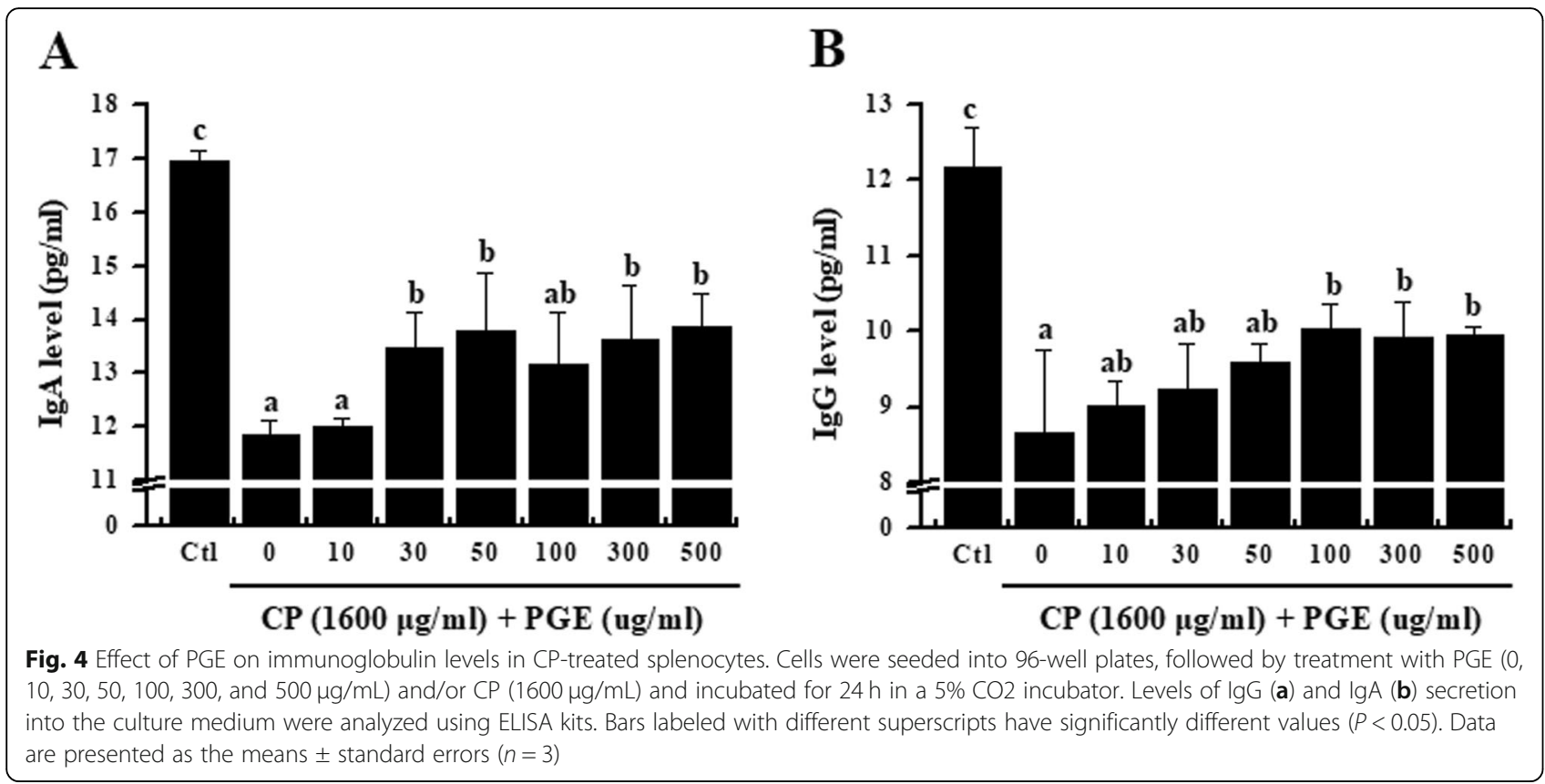

Effects of PGE on serum levels of IgG and IgA in CPinduced immunosuppressed rats

To understand the mechanism underlying PGE immunoregulatory activity, serum IgG and IgA levels in immunosuppressed rats (CP-treated) were determined by ELISA. As shown in Fig. 8, serum IgG and IgA levels were significantly decreased in the background of CPinduced immunosuppression. However, PGE-treated rats exhibited increased serum IgG and IgA levels compared to non-PGE-treated rats, further confirming that PGE improved the humoral immune response in immunosuppressed rats.

Effect of PGE on spleen and thymus damage in CPinduced immunosuppressed rats

We examined the morphological changes in the spleen and thymus, and also evaluated the effects of PGE treatment on these immune organs. Hematoxylin and eosin
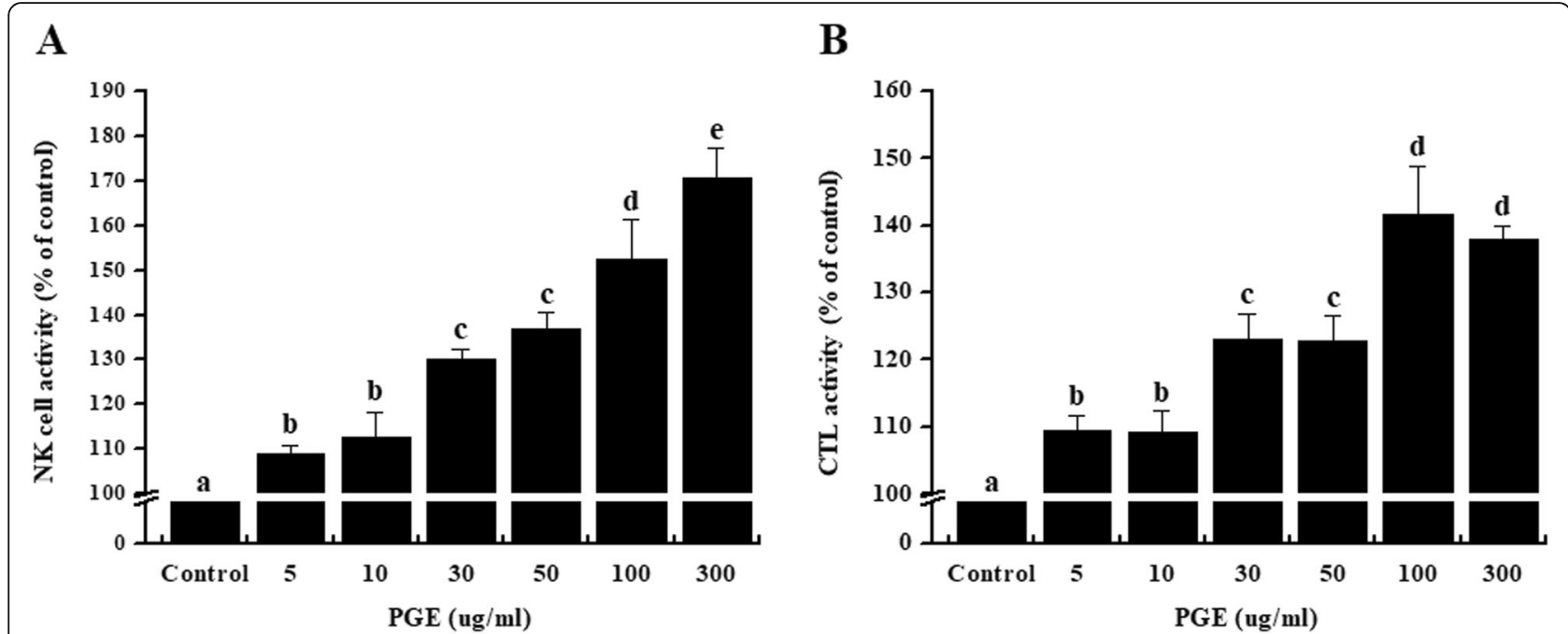

Fig. 5 Effect of PGE on splenic NK cell and CTL cytotoxicity in splenocytes. Splenocytes were prepared and assayed for NK cell (a) and CTL (b) activity using the WST-1 assay. Splenocytes were co-cultured with target cells (AR42J or HL-60) for NK cell or CTL activity, respectively, in 96-well plates, followed by treatment with PGE $(0,5,10,30,50,100$, and $300 \mu \mathrm{g} / \mathrm{mL})$ and incubated for $24 \mathrm{~h}$ in a $5 \% \mathrm{CO}_{2}$ incubator with an effector to target cell ratio of 25:1. NK cell and CTL activities were calculated as the survival rate of AR42J or HL-60 cells compared to that of control cells. Bars labeled with different superscripts have significantly different values $(P<0.05)$. Data are presented as the means \pm standard error $(n=3)$ 


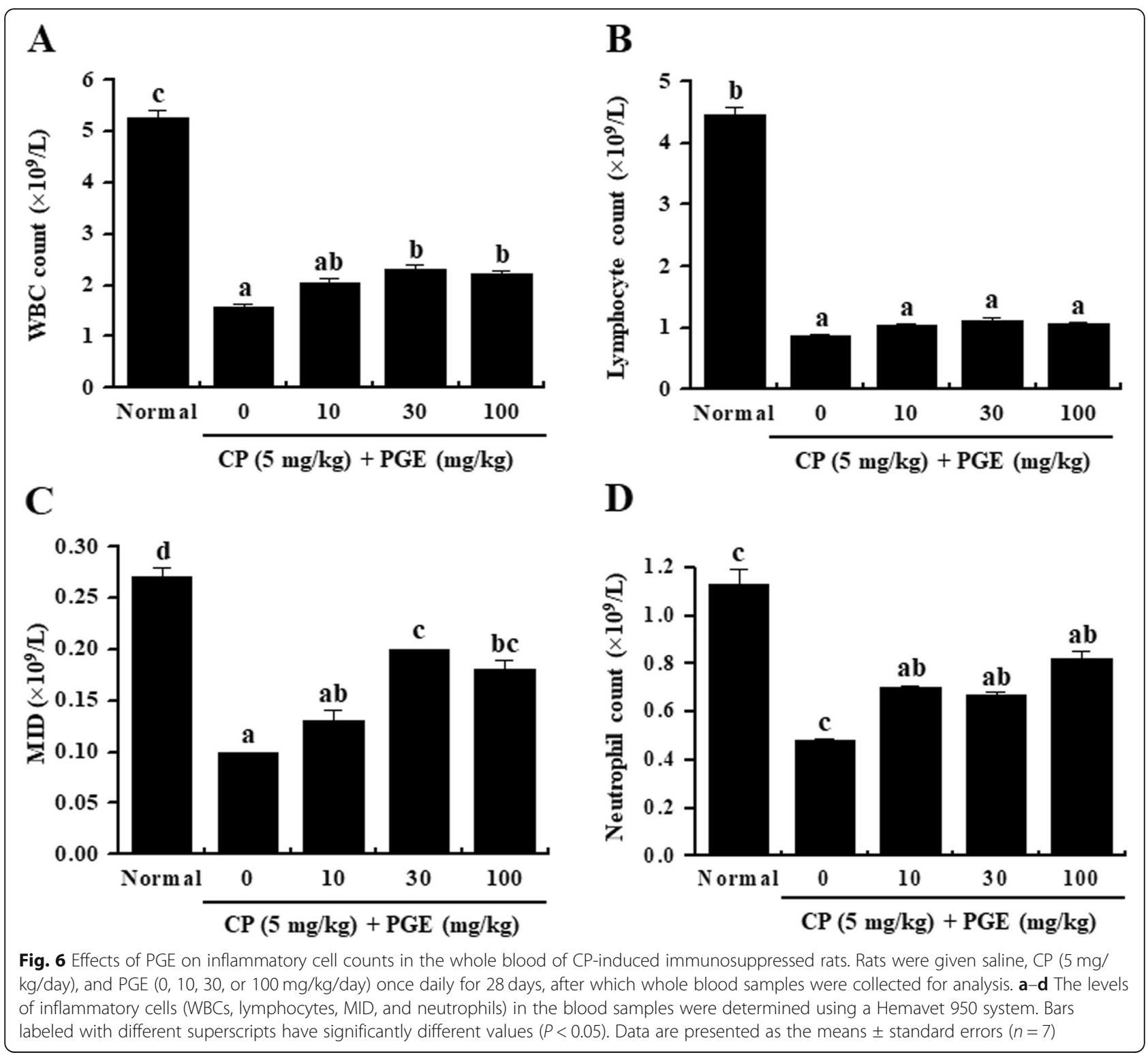

staining of the spleen showed that 30 and $100 \mathrm{mg} / \mathrm{kg}$ of PGE facilitated spleen cell multiplication and increased the percentage of white pulp, compared to the control group (Fig. 9a). In the thymus, the PGE-treated group exhibited a reduction of the phenomenon whereas the thymus cells, which showed deformation, nuclear condensation, and fragmentation, were separated from the surrounding tissues in a multifocal manner in the cortex (Fig. 9b). Together, these results indicate that PGE stimulates innate and adaptive immunity by restoring the histopathology of the spleen and thymus structures that were damaged by CP treatment.

\section{Discussion}

The study of immune-enhancing effects of natural products represents an active area of current research $[18,25,26]$.
Previous studies have reported immune enhancement following administration of PG [27, 28]. However, these reports have only determined the effect of PG on immune enhancement of lymphocytes and macrophages. In this study, we first showed that PG could revert the immunosuppression caused by CP. Specifically, PGE-treatment alleviated $\mathrm{CP}$-induced reduction in cell proliferation, cytokine and immunoglobulin levels, and NK cell and CTL activity in splenocytes. Additionally, PGE increased immune cell numbers and serum cytokines and immunoglobulin levels, and stimulated the recovery of the spleen and thymus in immunosuppressed rats. These findings indicate that PGE improves the weakened immune response brought about by $\mathrm{CP}$ treatment.

$\mathrm{CP}$ is an important chemotherapeutic drug in tumor therapy, but it is not beneficial for healthy cells and side 


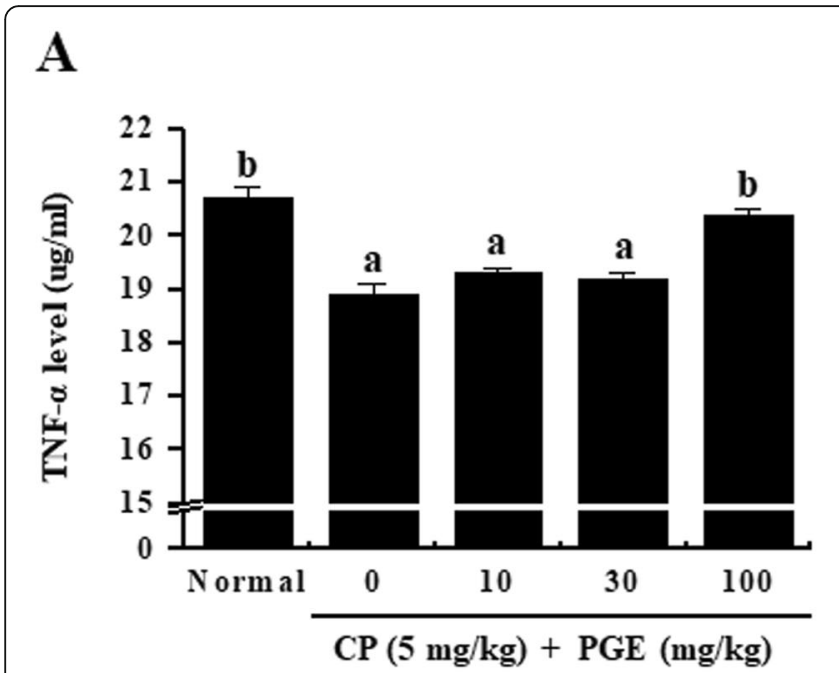

\section{B}

C

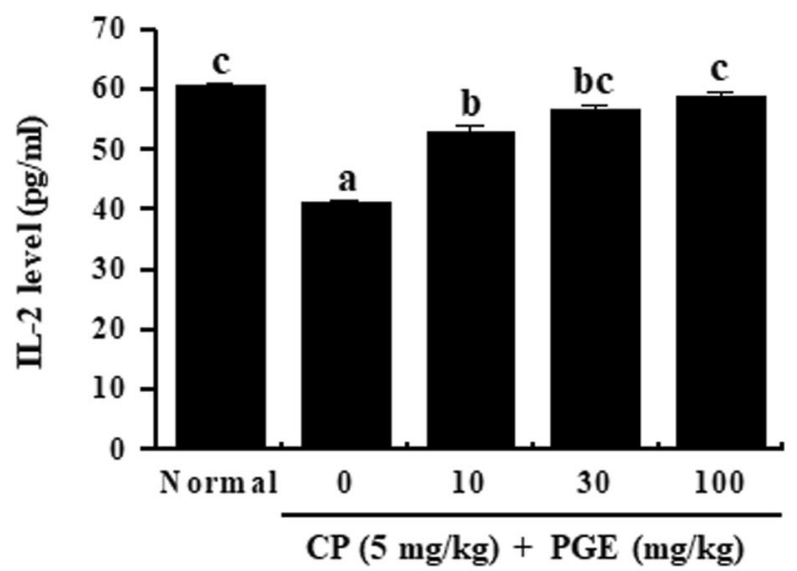

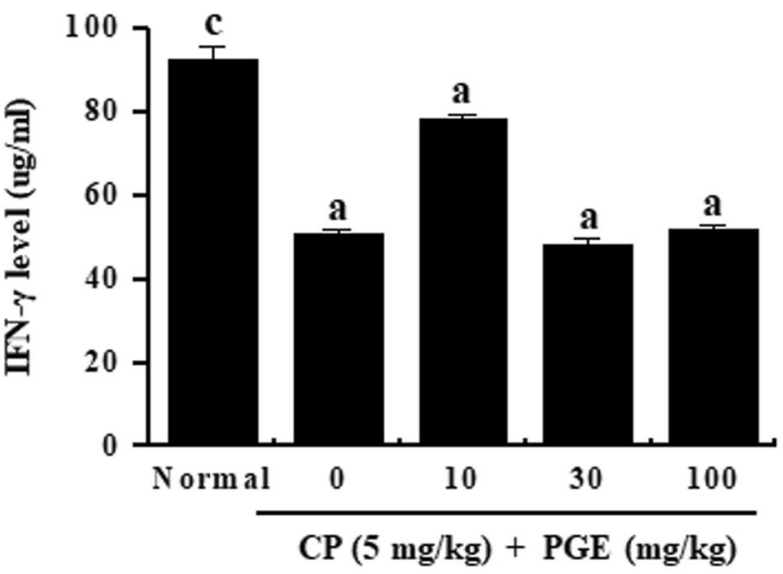

D

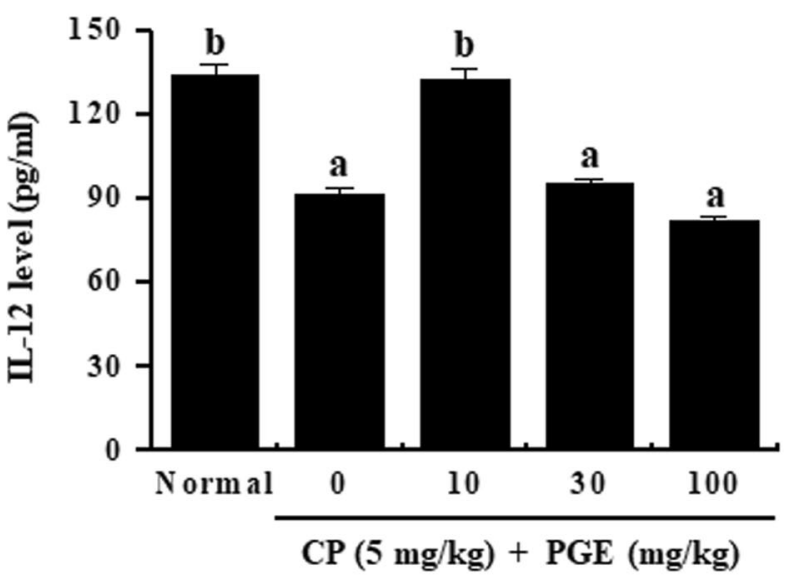

Fig. 7 Effect of PGE on the plasma levels of immune-related cytokines in the sera of CP-induced immunosuppression rats. Rats were given saline, CP $(5 \mathrm{mg} / \mathrm{kg} /$ day), and PGE $(0,10,30$, or $100 \mathrm{mg} / \mathrm{kg} /$ day) once daily for 28 days, after which the serum levels of TNF-a (a), IFN- $\gamma$ (b), IL-2 (c), and IL-12 (d) were quantified using ELISA kits. Bars labeled with different superscripts have significantly different values $(P<0.05)$. Data are presented as the means \pm standard errors $(n=7)$

effects such as bone marrow suppression, immunosuppression, oxidative stress, and occasionally life-threatening effects, are often observed [29]. In previous studies, CPtreated rats have been used as immunosuppression models in animals. CP-induced immunosuppression significantly reduces red blood cell, WBC, and platelet counts, and additionally inhibits spleen NK cell and CTL activity, as well as decreasing CD4 T lymphocyte count and the $\mathrm{CD} 4 / \mathrm{CD} 8$ ratio [30, 31]. In addition, the levels of cytokines (IL-2, IFN, and IL-10) and immunoglobulins (IgA, IgM, and IgG), along with serum hemoglobin, were reduced by $\mathrm{CP}$ [32]. Moreover, administration of $\mathrm{CP}$ has been shown to cause damage to the spleen and thymus, which are important organs in the immune response [33]. Thus, we investigated the immune-enhancing effects of PGE under conditions of CP-induced immunosuppression in this study.
Proliferation of macrophages and lymphocytes is important in the early activation stage of cellular and humoral immune responses. Splenocytes are composed of various cells, such as $\mathrm{T}$ and $\mathrm{B}$ cells, macrophages, and dendritic cells with different immune functions [34]. Stimulation of splenocytes proliferation ultimately increases the expression of cytokines, potentially improving cell-mediated immune responses and leading to immune-enhancement [35]. We found that PGE reversed the effect of reduced immune cell viability caused by CP (Fig. 2b and Fig. 6).

Cytokines expressed by various immune cells play an important role in lymphocyte differentiation, inflammation control, host defenses against bacterial infection, cell survival, apoptosis, and the immune response [36, 37]. Th cells activated after antigen recognition are classified into Th1 and Th2 cells 

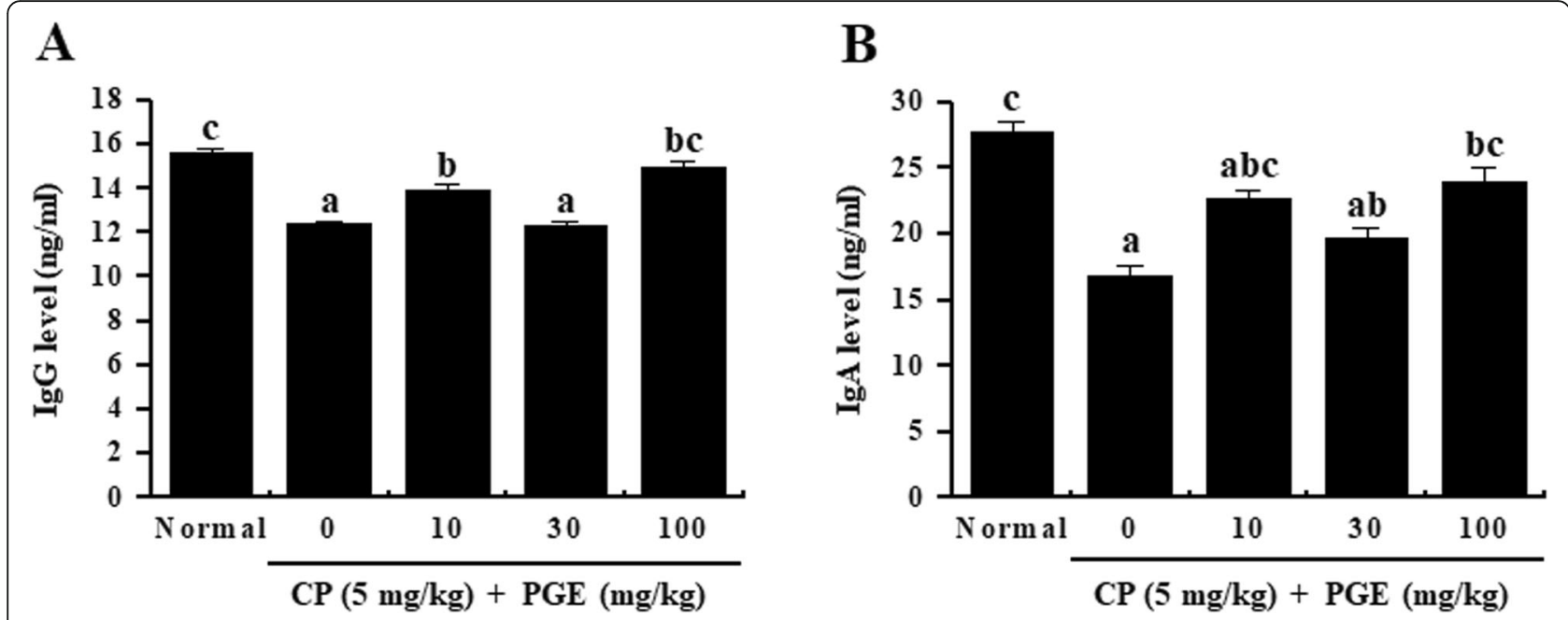

Fig. 8 Effect of PGE on plasma levels of immunoglobulins in the sera of CP-induced immunosuppressed rats. Rats were given saline, CP (5 mg/ $\mathrm{kg} /$ day), and PGE $(0,10,30$, or $100 \mathrm{mg} / \mathrm{kg} /$ day) once daily for 28 days, after which the serum levels of $\operatorname{lgG}(\mathbf{a})$ and $\operatorname{lgA}(\mathbf{b})$ were quantified using ELISA kits. Bars labeled with different superscripts have significantly different values $(P<0.05)$. Data are presented as the means \pm standard errors $(n=7)$

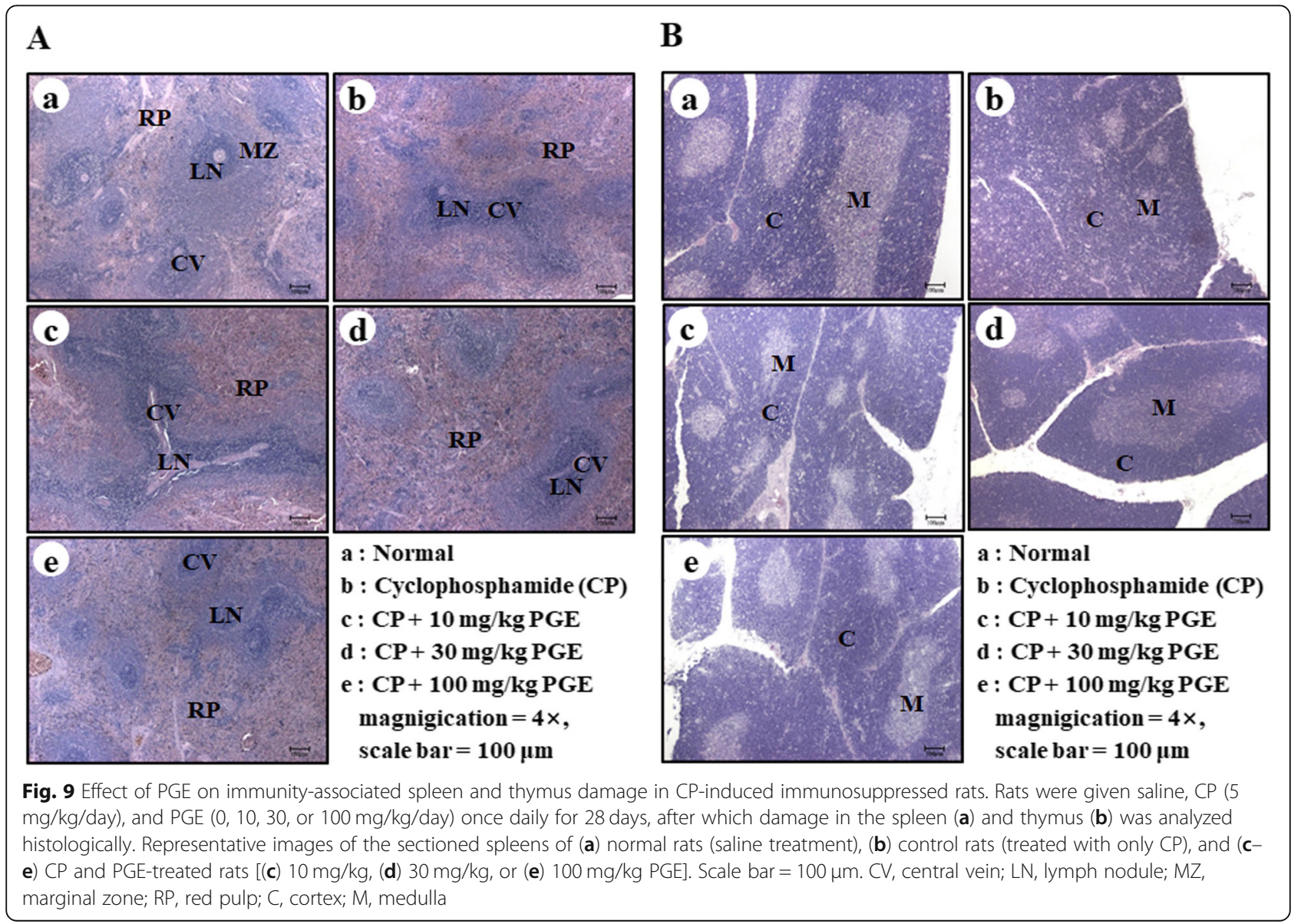


based on their function and differences in cytokines secreted [38, 39] . The different types of cytokines secreted by Th1 and Th 2 cells are important factors in determining cell function. Th1 cells secrete IL-2, TNF- $\alpha$, and IFN- $\gamma$, which are involved in cellmediated immune responses [40, 41], whereas Th2 cells mainly secrete IL-4, IL-6, and IL-10 through the humoral immune response [42]. In particular, TNF- $\alpha$ is produced by T and B cells, NK cells, and macrophages, and regulates inflammation and the host defense through inhibiting bacterial infections and suppressing acute stress $[43,44]$. IFN- $\gamma$ and IL-2 are produced by T-helper cells [45]. IFN- $\gamma$ is a natural immune mediator that promotes the expression of major histocompatibility complex molecules through activation of monocytes/macrophages [46]. IL-2, produced by activated $\mathrm{T}$ lymphocytes, induces growth, proliferation, and differentiation of immature $\mathrm{T}$ cells into effector $\mathrm{T}$ cells [47]. Finally, IL-12 is known to be produced by a variety of immune cells, including dendritic cells, macrophages, neutrophils, and human B-lymphocytes. It is responsible for differentiating native $\mathrm{T}$ lymphocytes into Th1 lymphocytes [48], and promotes the production of TNF- $\alpha$ and IFN- $\gamma$ in $\mathrm{T}$ lymphocytes and NK cells, respectively $[49,50]$. Therefore, we confirmed the effect of PGE on the expression of Th1 cytokines, and hypothesized that PGE would promote the Th1 immune response under conditions of $\mathrm{CP}$-induced immunosuppression (Fig. 3 and Fig. 7).

IgG, IgA, and IgM comprise major immunoglobulins that play a role in the neutralization of toxins, bacteria, or viruses, along with opsonization and complement activation [51]. Recently, numerous studies have reported that natural products can enhance the humoral immune response by promoting the production of IgA, IgM, and IgG [16]. Our results demonstrate that PGE can increase levels of IgG and IgA in CP-immunosuppressed rats. This result suggests that PGE plays a role in enhancing the humoral immune response.

NK cells and CTLs comprise two major populations that can target and kill foreign and abnormal cells. NK cells and CTLs play an important role in the early immune response [52]. NK cells and CTLs are activated by stimulation of cytokines and chemokines and play a central role in the regulation of tumor growth and metastasis, as well as the removal of viruses [52]. Thus, measurement of NK cell and CTL activity represents a useful method for assessing the cellular immune response of the host [53]. Our results showed that spleen NK cell cytotoxic activity was significantly increased after treatment with PGE (Fig. 5). Additionally, we assessed the NK cell and CTL activity of Red ginseng extract (RGE) as a positive control, and found that, although the RGE extracts were highly cytotoxic, NK cell activity was greater in the RGE group than in the PGE group at concentrations below $50 \mu \mathrm{g} / \mathrm{mL}$. However, CTL activity was higher in the PGE group compared to the RGE group, and in particular, PGE had a pronounced effect on CTL activity, which was higher than for the RGE group (Additional file 1: Figure S1). These results suggest that PGE enhances the cell-mediated immune response through modulating NK cell activity.

Immunosuppression is a condition in which the immune system is not sufficiently activated to defend the host from infections. The immune system can be weakened by various factors, such as birth and aging, which may lead to shrinkage of immune tissues and a decrease in the number of WBCs [54]. Mature blood cells such as WBCs, red blood cells, and platelets are produced by hematopoietic stem cells, which are multipotent and self-renewable [55]. We found that, although $\mathrm{CP}$ treatment decreased the WBC, lymphocyte, MID, and neutrophil populations, consistent with prior reports [56], these cell counts were significantly restored by PGE administration in a dose-dependent manner. These results suggest that PGE enhances immunity by protecting against $\mathrm{CP}$-induced myelosuppression.

In addition, we confirmed the effect of PGE on CPinduced immune organ damage. Histopathological examination of the spleen and thymus of immunosuppressed rats (CP-treated) revealed CP-induced damage. Notably, PGE-treatment significantly reduced $\mathrm{CP}$-induced pathological changes in the spleen and thymus (Fig. 9), suggesting that PGE may in fact reverse the CP-induced atrophy in immune organs.

\section{Conclusion}

In summary, we demonstrated the immune-enhancing effects of PGE in CP-treated splenocytes using an immunosuppressed rat model. Our results confirmed that PGE stimulates innate and adaptive immune responses under immunosuppressive conditions, and increases cytokine, antibody, and immune cell production and NK cell and CTL activity, thereby enhancing the immune response and host defense. These findings suggest that PG may have applications in the development of functional foods and medicines that can be used for immuneenhancement.

\section{Supplementary information}

Supplementary information accompanies this paper at https://doi.org/10. 1186/s12906-019-2724-0.

Additional file 1: Figure S1. Effect of PGE compared to RGE on splenic NK cell activity in splenocytes. (A) Splenocytes were seeded into a 96-well plate with $\operatorname{RGE}(0,3,5,10,30,50,100,300,500,1000$ and $2000 \mu \mathrm{g} / \mathrm{mL})$. Cells were incubated for $24 \mathrm{~h}$ under $5 \% \mathrm{CO}_{2}$, and their viability was measured using a WST-1 Assay Kit. (B, C) Splenocytes were co-cultured with AR42J or 
HL-60 target cells to induce NK cell or CTL activity, respectively, in 96-well plates, followed by treatment with RGE $(0,5,10,30,50,100$, and $300 \mu \mathrm{g} / \mathrm{mL})$ and PGE $(0,5,10,30,50,100$, and $300 \mu \mathrm{g} / \mathrm{mL})$. Cells were then incubated for $24 \mathrm{~h}$ in a $5 \% \mathrm{CO}_{2}$ incubator with an effector to target cells ratio of 25:1. NK cell and CTL activities were calculated as the survival rate of AR42J or HL-60 cells compared to that of control cells. Bars labeled with different superscripts have significantly different values $(P<0.05)$. Data are presented as the means \pm standard errors $(n=3)$.

\section{Abbreviations}

CBC: Complete blood count; CP: Cyclophosphamide; CTL: Cytotoxic T lymphocyte; MID: Mid-range absolute counts; NK: Natural killer; PGE: P. grandiflorum extract

\section{Acknowledgements}

Not applicable.

\section{Authors' contributions}

YRL and HYL designed the study. EMN, JMK and HKS performed the experiments. MJK, HJY and KSK analyzed the data. S. Jung provided the roots of Platycodon grandiflorum and provided comments and editorial review of the manuscript. YRL drafted the manuscript. All authors read and approved the final manuscript.

\section{Funding}

This work was supported by "Food Functionality Evaluation program" under the Ministry of Agriculture (no. 31607203), Food and Rural Affairs and National Research Council of Science \& Technology (NST) grant by the Korea Government (MSIP) (no. CAP-16-07-KIOM) and Korea Food Research Institute (E015302-05). The funding bodies had no involvement in the concept, design, analysis or writing the manuscript.

\section{Availability of data and materials}

The datasets analyzed during the current study are available from the corresponding author on reasonable request.

\section{Ethics approval and consent to participate}

This animal study was approved by the Committee on Care and Use of Laboratory Animals of Wonkwang University.

\section{Consent for publication}

Not applicable.

\section{Competing interests}

The authors declare that they have no competing of interests.

\section{Author details}

'Department of Oral Biochemistry, and Institute of Biomaterial-Implant, College of Dentistry, Wonkwang University, 460, Iksandae-ro, Iksan, Jeonbuk 54538, Republic of Korea. ${ }^{2}$ INVIVO Co. Ltd., 310, GVSC, Iksandae-ro, Iksan, Jeonbuk 54538, Republic of Korea. ${ }^{3}$ JIRISANDONGUICHON Co. Ltd, 2000-89 Sincha-ro, Chahwang-myeon, Sancheong, Gyeongnam 52206, Republic of Korea. ${ }^{4}$ Korea Food Research Institute, 245, Nongsaengmyeong-ro, Iseo-myeon, Wanju-gun, Jeollabuk-do 55365, Republic of Korea. ${ }^{5}$ Department of Food Science and Nutrition, Yong In University, Yongin, Gyeonggi-do 17092, Republic of Korea.

\section{Received: 1 February 2019 Accepted: 22 October 2019}

\section{Published online: 21 November 2019}

\section{References}

1. Li W, Liu Y, Wang Z, Han Y, Tian YH, Zhang GS, Sun YS, Wang YP. Platycodin $\mathrm{D}$ isolated from the aerial parts of Platycodon grandiflorum protects alcohol-induced liver injury in mice. Food Funct. 2015;6(5):1418-27.

2. Zhang L, Wang Y, Yang D, Zhang C, Zhang N, Li M, Liu Y. Platycodon grandiflorus - an ethnopharmacological, phytochemical and pharmacological review. J Ethnopharmacol. 2015;164:147-61.

3. Han LK, Zheng YN, Xu BJ, Okuda H, Kimura Y. Saponins from platycodi radix ameliorate high fat diet-induced obesity in mice. J Nutr. 2002;132(8):2241-5.
4. Chun J, Joo EJ, Kang M, Kim YS. Platycodin D induces anoikis and caspasemediated apoptosis via p38 MAPK in AGS human gastric cancer cells. J Cell Biochem. 2013;114(2):456-70.

5. Wang C, Schuller Levis GB, Lee EB, Levis WR, Lee DW, Kim BS, Park SY, Park E. Platycodin D and D3 isolated from the root of Platycodon grandiflorum modulate the production of nitric oxide and secretion of TNF-alpha in activated RAW 264.7 cells. Int Immunopharmacol. 2004;4(8):1039-49.

6. Xie Y, Sun HX, Li D. Platycodin D improves the immunogenicity of Newcastle disease virus-based recombinant avian influenza vaccine in mice. Chem Biodivers. 2010;7(3):677-89.

7. Han EH, Park JH, Kim JY, Chung YC, Jeong HG. Inhibitory mechanism of saponins derived from roots of Platycodon grandiflorum on anaphylactic reaction and IgE-mediated allergic response in mast cells. Food Chem Toxicol. 2009;47(6):1069-75.

8. Springer TA. Adhesion receptors of the immune system. Nature. 1990; 346(6283):425-34.

9. Wynn TA, Chawla A, Pollard JW. Macrophage biology in development, homeostasis and disease. Nature. 2013;496(7446):445-55.

10. Spiering MJ. Primer on the immune system. Alcohol Res. 2015;37(2):171-5.

11. Raj S, Gothandam KM. Immunomodulatory activity of methanolic extract of Amorphophallus commutatus var. wayanadensis under normal and cyclophosphamide induced immunosuppressive conditions in mice models. Food Chem Toxicol. 2015;81:151-9.

12. Shin JS, Chung SH, Lee WS, Lee JY, Kim JL, Lee KT. Immunostimulatory effects of cordycepin-enriched WIB-801CE from Cordyceps militaris in splenocytes and cyclophosphamide-induced immunosuppressed mice. Phytother Res. 2018;32(1):132-9.

13. Pass GJ, Carrie D, Boylan M, Lorimore S, Wright E, Houston B, Henderson CJ, Wolf CR. Role of hepatic cytochrome p450s in the pharmacokinetics and toxicity of cyclophosphamide: studies with the hepatic cytochrome p450 reductase null mouse. Cancer Res. 2005;65(10):4211-7.

14. Tripathi DN, Jena GB. Intervention of astaxanthin against cyclophosphamide-induced oxidative stress and DNA damage: a study in mice. Chem Biol Interact. 2009;180(3):398-406.

15. Zhou Y, Chen X, Yi R, Li G, Sun P, Qian Y, Zhao X. Immunomodulatory Effect of Tremella Polysaccharides against Cyclophosphamide-Induced Immunosuppression in Mice. Molecules. 2018;23(2). https:/doi.org/10.3390/molecules23020239.

16. Yu Q, Nie SP, Wang JQ, Liu XZ, Yin PF, Huang DF, Li WJ, Gong DM, Xie MY. Chemoprotective effects of Ganoderma atrum polysaccharide in cyclophosphamide-induced mice. Int J Biol Macromol. 2014;64:395-401.

17. Haddad PS, Azar GA, Groom S, Boivin M. Natural health products, modulation of immune function and prevention of chronic diseases. Evid Based Complement Alternat Med. 2005;2(4):513-20.

18. Wang K, Conlon M, Ren W, Chen BB, Baczek T. Natural products as targeted modulators of the immune system. J Immunol Res. 2018;2018:7862782.

19. Li W, Tian YH, Liu Y, Wang Z, Tang S, Zhang J, Wang YP. Platycodin D exerts anti-tumor efficacy in $\mathrm{H} 22$ tumor-bearing mice via improving immune function and inducing apoptosis. J Toxicol Sci. 2016;41(3):417-28.

20. Lee HY, Park YM, Lee YH, Kang YG, Lee HM, Park DS, Yang HJ, Kim MJ, Lee YR. Immunostimulatory effect of Zanthoxylum schinifolium-based complex oil prepared by supercritical fluid extraction in Splenocytes and cyclophosphamide-induced immunosuppressed rats. Evid Based Complement Alternat Med. 2018;2018:8107326.

21. Medzhitov R, Janeway CA Jr. Innate immunity: impact on the adaptive immune response. Curr Opin Immunol. 1997;9(1):4-9.

22. Aggarwal BB. Signalling pathways of the TNF superfamily: a double-edged sword. Nat Rev Immunol. 2003;3(9):745-56.

23. Boyman O, Sprent J. The role of interleukin-2 during homeostasis and activation of the immune system. Nat Rev Immunol. 2012;12(3):180-90.

24. Lin PL, Plessner HL, Voitenok NN, Flynn JL. Tumor necrosis factor and tuberculosis. J Invest Dermatol Symp Proc. 2007;12(1):22-5.

25. Fang Q, Wang JF, Zha XQ, Cui SH, Cao L, Luo JP. Immunomodulatory activity on macrophage of a purified polysaccharide extracted from Laminaria japonica. Carbohydr Polym. 2015;134:66-73.

26. Lee J, Choi JW, Sohng JK, Pandey RP, Park YI. The immunostimulating activity of quercetin 3-O-xyloside in murine macrophages via activation of the ASK1/MAPK/NF-kappaB signaling pathway. Int Immunopharmacol. 2016; 31:88-97.

27. Kim EH, Gwak JY, Chung MJ. Immunomodulatory activity of Platycodon grandiflorum, Codonopsis lanceolata, and Adenophora triphylla extracts in macrophage cells. Korean Soc Food Nutr. 2018;47(11):1069-75. 
28. Zhao X, Wang Y, Yan P, Cheng G, Wang C, Geng N, Wang X, Liu J. Effects of Polysaccharides from Platycodon grandiflorum on immunityenhancing activity in vitro. Molecules. 2017;22(11). https://doi.org/10. 3390/molecules22111918.

29. Wang H, Wang M, Chen J, Tang Y, Dou J, Yu J, Xi T, Zhou C. A polysaccharide from Strongylocentrotus nudus eggs protects against myelosuppression and immunosuppression in cyclophosphamide-treated mice. Int Immunopharmacol. 2011;11(11):1946-53.

30. Diwanay S, Chitre D, Patwardhan B. Immunoprotection by botanical drugs in cancer chemotherapy. J Ethnopharmacol. 2004;90(1):49-55.

31. Huang GC, Wu LS, Chen LG, Yang LL, Wang CC. Immuno-enhancement effects of Huang qi Liu Yi Tang in a murine model of cyclophosphamideinduced leucopenia. J Ethnopharmacol. 2007;109(2):229-35.

32. Hu TJ, Shuai XH, Chen JR, Wei YY, Zheng RL. Protective effect of a Potentilla anserine polysaccharide on oxidative damages in mice. Int J Biol Macromol. 2009;45(3):279-83.

33. Li WJ, Li L, Zhen WY, Wang LF, Pan M, LV JQ, Wang F, Yao YF, Nie SP, Xie MY. Ganoderma atrum polysaccharide ameliorates ROS generation and apoptosis in spleen and thymus of immunosuppressed mice. Food Chem Toxicol. 2017;99:199-208.

34. Klimp AH, de Vries EG, Scherphof GL, Daemen T. A potential role of macrophage activation in the treatment of cancer. Crit Rev Oncol Hematol. 2002;44(2):143-61.

35. Zeng G, Ju Y, Shen H, Zhou N, Huang L. Immunopontentiating activities of the purified polysaccharide from evening primrose in $\mathrm{H} 22$ tumor-bearing mice. Int J Biol Macromol. 2013:52:280-5.

36. Lacy P, Stow JL. Cytokine release from innate immune cells: association with diverse membrane trafficking pathways. Blood. 2011;118(1):9-18.

37. Van der Meide PH, Schellekens $\mathrm{H}$. Cytokines and the immune response. Biotherapy. 1996;8(3-4):243-9.

38. Zhou X, Luo L, Dressel W, Shadier G, Krumbiegel D, Schmidtke P, Zepp F, Meyer CU. Cordycepin is an immunoregulatory active ingredient of Cordyceps sinensis. Am J Chin Med. 2008;36(5):967-80.

39. Osugi Y, Hara J, Tagawa S, Takai K, Hosoi G, Matsuda Y, Ohta H, Fujisaki $\mathrm{H}$, Kobayashi M, Sakata N, et al. Cytokine production regulating Th1 and Th2 cytokines in hemophagocytic lymphohistiocytosis. Blood. 1997; 89(11):4100-3.

40. McAleer JP, Vella AT. Understanding how lipopolysaccharide impacts CD4 Tcell immunity. Crit Rev Immunol. 2008;28(4):281-99.

41. Tough DF, Sun S, Sprent J. T cell stimulation in vivo by lipopolysaccharide (LPS). J Exp Med. 1997;185(12):2089-94.

42. Decker T, Muller M, Stockinger S. The yin and yang of type I interferon activity in bacterial infection. Nat Rev Immunol. 2005;5(9):675-87.

43. Giai C, Gonzalez C, Ledo C, Garofalo A, Di Genaro MS, Sordelli DO, Gomez MI. Shedding of tumor necrosis factor receptor 1 induced by protein a decreases tumor necrosis factor alpha availability and inflammation during systemic Staphylococcus aureus infection. Infect Immun. 2013;81(11):4200-7.

44. Connor TJ, Brewer C, Kelly JP, Harkin A. Acute stress suppresses proinflammatory cytokines TNF-alpha and IL-1 beta independent of a catecholamine-driven increase in IL-10 production. J Neuroimmunol. 2005; 159(1-2):119-28.

45. Kaiko GE, Horvat JC, Beagley KW, Hansbro PM. Immunological decisionmaking: how does the immune system decide to mount a helper T-cell response? Immunology. 2008;123(3):326-38.

46. Schroder K, Hertzog PJ, Ravasi T, Hume DA. Interferon-gamma: an overview of signals, mechanisms and functions. J Leukoc Biol. 2004;75(2):163-89.

47. Zhang P, Tey SK, Koyama M, Kuns RD, Olver SD, Lineburg KE, Lor M, Teal BE, Raffelt NC, Raju J, et al. Induced regulatory T cells promote tolerance when stabilized by rapamycin and IL-2 in vivo. J Immunol. 2013;191(10):5291-303.

48. Dorman SE, Holland SM. Interferon-gamma and interleukin-12 pathway defects and human disease. Cytokine Growth Factor Rev. 2000;11(4):321-33.

49. Watford WT, Moriguchi M, Morinobu A, O'Shea JJ. The biology of IL-12: coordinating innate and adaptive immune responses. Cytokine Growth Factor Rev. 2003;14(5):361-8.

50. Hsieh CS, Macatonia SE, Tripp CS, Wolf SF, O'Garra A, Murphy KM. Development of TH1 CD4+ T cells through IL-12 produced by listeriainduced macrophages. Science. 1993;260(5107):547-9.

51. Schroeder HW Jr, Cavacini L. Structure and function of immunoglobulins. Allergy Clin Immunol. 2010;125(2 Suppl 2):S41-52.
52. Kos FJ, Engleman EG. Immune regulation: a critical link between NK cells and CTLs. Immunol Today. 1996;17(4):174-6.

53. Elemans M, Thiebaut R, Kaur A, Asquith B. Quantification of the relative importance of CTL, B cell, NK cell, and target cell limitation in the control of primary SIV-infection. PLoS Comput Biol. 2011;7(3):e1001103.

54. Gandhi GR, Neta M, Sathiyabama RG, Quintans JSS, de Oliveira ESAM, Araujo AAS, Narain N, Junior LJQ, Gurgel RQ. Flavonoids as Th1/Th2 cytokines immunomodulators: a systematic review of studies on animal models. Phytomedicine. 2018;44:74-84.

55. Moore KA, Lemischka IR. Stem cells and their niches. Science. 2006; 311(5769):1880-5.

56. Davis L, Kuttan G. Effect of Withania somnifera on cytokine production in normal and cyclophosphamide treated mice. Immunopharmacol Immunotoxicol. 1999;21(4):695-703.

\section{Publisher's Note}

Springer Nature remains neutral with regard to jurisdictional claims in published maps and institutional affiliations.
Ready to submit your research? Choose BMC and benefit from:

- fast, convenient online submission

- thorough peer review by experienced researchers in your field

- rapid publication on acceptance

- support for research data, including large and complex data types

- gold Open Access which fosters wider collaboration and increased citations

- maximum visibility for your research: over $100 \mathrm{M}$ website views per year

At BMC, research is always in progress.

Learn more biomedcentral.com/submissions 